\title{
Product Lifespan: The Missing Link in Servitization
}

\section{Ferran Vendrell-Herrero}

Birmingham Business School, University of Birmingham, United Kingdom

Email: f.vendrell-herrero@bham.ac.uk

\section{Yancy Vaillant}

Department of Strategy, Entrepreneurship \& Innovation, Toulouse Business School, France

Email: y.vaillant@tbs-education.org

\section{Oscar F. Bustinza}

Department of Management I, Universidad de Granada, Spain

Email: oscarfb@ugr.es

\section{Esteban Lafuente}

Department of Management, Universitat Politècnica de Catalunya, Spain Email: esteban.lafuente@upc.edu

\section{Working paper version \\ December 2020}

\section{Please cite as:}

Vendrell-Herrero, F., Vaillant, Y., Bustinza, O.F., Lafuente, E. (2021). Product lifespan: the missing link in servitization, Production Planning \& Control, doi:

https://doi.org/10.1080/09537287.2020.1867773 


\section{Product Lifespan: The Missing Link in Servitization}

By drawing on a business model lens, this study proposes that the competitive performance of servitization is higher for manufacturing firms selling longlifespan products since they better develop the key elements required for transitioning towards integrated Business to Business (BtoB) solutions delivery. Additionally, the study argues that the moderation role of product lifespan is stronger in advanced stages of servitization as it reduces replacement and information costs. To test these hypotheses, this study merges a unique survey of Manufacturing Multinational Enterprises (MMNEs) and the Lifespan Database for Vehicles, Equipment and Structures (LiVES). Results show a positive moderating effect of product lifespan in the relationship between servitization and performance. Following this finding, across firms with high-intensity servitization, the firm that sells longest-lifespan products is predicted to capture most value from servitization. Overall, the present study suggests that implementation of recurrent services during an extended product lifecycle provides an opportunity for BtoB solutions delivery and product usage optimization. By including product lifespan in the equation, we improve understanding of why servitization is an excellent mechanism for managing longlasting industrial relationships, and explain why servitization boosts performance in some manufacturing industries but has a neutral effect on others.

Keywords: Servitization; Business-to-Business; Solution business models; Product lifespan; Competitive performance

"When companies take so-called servitization steps toward solutions, they concurrently change their earning logic, move their position in the value network, and need to use and develop capabilities in a different way - inherently making fundamental business model changes”

—Storbacka et al. (2013, 705).

\section{Introduction}

Manufacturers are increasingly pushed to transition from a standardized product business model towards a solution model that offers greater customization and responds 
to the specific needs of each customer (Storbacka and Nenonen 2009; Storbacka et al. 2013). Rising market orientation (Na, Kang, and Jeong 2019) as well as increased information availability and affordability (Ganotakis, Hsieh, and Love 2013) together with the limited scope of cost leadership strategies for manufacturers within a knowledge-based economy (Grant and Baden-Fuller 2004) have combined with advances in production techniques to drive manufacturers towards greater personalization. By offering customized solutions, producers are adding greater value to their products (Storbacka 2011; Zhou et al. 2020). Manufacturers are therefore brought to develop organizational capabilities and invest relational capital that will allow them to transition towards vertical life-cycle product-service solution delivery (Gebauer, Paiola, and Saccani 2013). As such, one aspect that requires further attention is product longevity. As theoretically argued by Storbacka et al. (2012), product longevity is the missing link that enable the successful delivery of a solution-based model. Despite its relevance, the analysis of this theoretical argument has been sidelined in prior empirical research. The present study fills this gap by investigating the moderating effect of product lifespan in the servitization-performance relationship.

With increased product longevity, manufacturers require the development of intangible internal capabilities that enable the formation of closer relationships with customers (Rapaccini and Visintin 2015). Consequently, intangible assets are crucial for manufacturers in their efforts to provide value added (Löfberg, Witell, and Gustafsson 2010; Teece 1998) and to achieve competitive advantage (Arrighetti, Landini, and Lasagni 2014). Intangible assets materialize as economic value in the form of services which, when developed in the context of product firms, require organizational change known as servitization (Baines et al. 2017; Calabrese et al. 2019; Rabetino et al. 2018; Vandermerwe and Rada 1988). Offering complementary services is increasingly 
important for manufacturers, as it enables them to co-create with users and more easily personalize their products (Storbacka et al. 2012). As a result, manufacturers can establish more lasting relationships with end consumers than they would with the simple transactions associated with traditional business models based on the guileless sale of products (Bigdeli et al. 2018a; Fliess and Lexutt 2019; Storbacka and Nenonen 2009; Wise and Baumgartner 1999).

But the transition towards a solution business model is not of equal value to all manufacturers (Kamp 2019; Nordin and Kowalkowski 2010; Wang, Lai, and Shou 2018). Indeed, the more extraordinary and strategic the purchase is for the buyer, and the more the purchase represents an important investment, the greater the importance of offering customization (Dachs, Kinkel, and Jäger 2014). This is especially the case when the products being transacted have substantial lifespans and involve outcomebased customized contracts (Ng, Ding, and Yip, 2013). These contracts are the most advanced level of service offering that manufacturers can provide (Visnjic et al., 2017), offering solutions where long-term contracts match service lifespan (Paiola et al., 2013). When product lifespan is long and akin to the service lifespan, there will be a considerable reduction of replacement and information costs (Hypko, Tilebein \& Gleich, 2010; Richter, Sadek \& Steven, 2010). Therefore, under these circumstances, the impact of servitization over the manufacturers' performance is likely enhanced (Baines et al. 2019). This can especially be the case when Business to Business (BtoB) value chain relationships are involved (Bastl 2012; Heirati and Siahtiri 2019). The customized added value of the service-augmented solutions that BtoB manufacturers deliver to their customers carries far greater potential of forming part of the differentiation at the basis of the clients' competitiveness, instilling a symbiotic relationship between both that welds better with longer-term relationships. 
This study argues that the importance of servitization for the performance of manufacturers is in part explained by the longevity of the product commercialized. Long lifespan products are especially susceptible to the benefits of servitization as conducer of customized value-added from a more solution-oriented business model. This is due to the importance of relational longevity and product lifespan for the proper delivery of high-value solutions as well as the complexity of maintenance and substantial asset management effort of such BtoB product-service systems (Bustinza, Vendrell-Herrero, and Baines 2017). Product longevity also allows servitization to better reach the customer embeddedness and solution integration benefits as well as the organizational networkedness and operational adaptiveness, which are key for manufacturers to transition towards a BtoB solution business model (Storbacka et al. 2013).

We respond to recent calls requesting new studies contextualizing various aspects of servitization (Dmitrijeva et al. 2019). In particular, this study contributes to the relevant literature by contextualizing the relationship between servitization and performance in different manufacturing sectors offering products with short and long lifespans. To achieve this goal, we consider manufacturing firms that supply products with a varied range of lifespans. Our study's hypotheses thus seek to determine whether servitization is more beneficial for firms with lasting products than for firms whose products have a shorter lifespan. Moreover, the study also examines if this moderation role of product lifespan is stronger in firms that reach more advanced stages within the servitization continuum (e.g outcome base contracts).

This study tests its hypotheses with a unique cross-section sample of 301 manufacturing multinational firms (MMNEs) that operate worldwide in conjunction with LiVES (Lifespan Database for Vehicles, Equipment and Structures), a database 
that provides information about the average products’ lifespan for a number of industries (Murakami et al. 2010; Oguchi et al. 2010). By comparing the relationship between servitization and performance in these industries, our results support the hypotheses. An important contribution of this study is thus to provide a first quantitative test to confirm that servitization becomes a decisive strategy that helps manufacturers offer customized solutions, raising the value-added of the products offered based on their lifespan.

The article is organized as follows. The next section presents the concepts of solution business model, servitization and product lifespan and develops the study’s hypotheses connecting these variables to business performance. The sample, variables and method are described in the third section, while Section 4 presents the empirical results. The fifth section concludes with a theoretical discussion of the results and their implications for future research.

\section{Theoretical framework and formulation of study hypotheses}

\section{Servitization as a means of offering solutions}

Manufacturing firms are increasingly adding more services to their product portfolios in a process of organizational change known as servitization, a term coined by Vandermerwe and Rada (1988). The process of servitization in the manufacturing industry began towards the end of the 1980s when firms realized the added-value that their products could generate with the incorporation of services (Rabetino, Kohtamäki, and Gebauer 2017). Wise and Baumgartner (1999) determine that industries like personal computers, the railway or the automotive industry only obtain $5 \%-20 \%$ of the total income that their products generated throughout their lifespan. The remaining percentage corresponding to services associated with these products. Along these lines, 
firms like Rolls-Royce introduce new business models of servitization such as Powerby-the-hour. In this business model, the manufacturer ceases to sell products and begins to sell business solutions for its customers, shifting from transactional, temporary relationships to continuous relationships in which customers pay for services delivered based on the use they make of the supplier's products (Smith 2013).

Servitization allows manufacturers to transition from a product business model to one of solutions offering greater value-added and more sustainable sources of competitive advantage (Bustinza et al. 2015). Baden-Fuller and Morgan (2010) described the product business model, which has been historically dominant amongst manufacturers, as a relationship where the supplier creates a product that is sold to the buyer. In such a business model, the value proposition is mostly transactional in nature and profitability is often associated with the scale of production (Baden-Fuller and Morgan 2010). A solution business model, that has come to characterize knowledgeintensive service providers, is a relationship where the supplier is first presented with a problem that the buyer faces; the supplier then provides an integrated solution to that problem that is sold to the buyer. The value proposition of the solution business model is in large measure relational in nature and comes from the customization of solutions to the specificities of each buyer's needs (Kharlamov and Parry 2020). An important difficulty with solution business models is its scalability, where greater production volumes tend to lead to higher marginal costs. This is especially an issue for manufacturers who largely rely on inflexible tangible resources for their production. Servitization, however, has come to represent an accessible means of customization for manufacturers that allows them to more easily transition from a product to a solution business model (Storbacka et al. 2013). 
Servitization allows manufacturers to transition towards a solution business model and overcome the production scalability limitations by making greater integrated use of more modular complementary services that are reliant on more mutable intangible resources (Sturgeon 2002). Servitization can thus permit manufacturers to obtain competitive advantages from the introduction of product-services systems on the firm’s knowledge of its customers (Bustinza et al. 2018). In this product-service interaction, firms develop certain intangible and specific capabilities that enable them to provide a wide range of base services associated with their products; from productoriented services such as replacements and guarantees, to result-oriented services, such as Power-by-the-Hour (Ng et al. 2012).

\section{Servitization and firm performance}

The literature analysing servitization uses different conceptual frameworks to classify the stages followed in the process of introducing services in production firms (Baines and Lightfoot 2013; Davies 2004; Mathieu 2001; Oliva and Kallenberg 2003; Tukker 2004). Most typologies of services supplied by manufacturing firms establish a continuum of intensity-based service aggregations.

Servitization forces firms to change their competitive dynamics in a positive way: helping them to adjust the process of strategic thinking (Vandermerwe and Rada, 1988); increasing organizations’ competitive capabilities (Lee, Yoo, and Kim 2016), which incorporates co-creation and the end consumers into their production and commercialization strategies (Rabetino et al. 2018); and encouraging analysis of the competitive environment from a new, eco-systemic perspective in which new strategic alliances can play a decisive role in obtaining a dominant competitive position (Alghisi and Saccani 2015; Cheng and Johansen 2014; Zhou et al. 2020). As a result of this strategic strengthening, various authors indicate that servitization contributes to greater 
stability in firms’ income (Gebauer and Friedli 2005), since they establish greater switching costs (Yang and Peterson 2004) and are less affected by the cost-based competitive strategies of rivals (Ulaga and Reinartz 2011). Not only can manufacturers offering product-service systems generate greater margins from their added-value, digitalization and differentiation (Abou-Foul, Ruiz-Alba and Soares 2020; Parida, Sjödin, and Reim, 2019; Sjödin et al., 2020; Sousa and da Silveira 2017), servitized firms are less dependent on economic cycle fluctuations (Ariu 2016). Servitization can shield manufacturers against the hazards of competing in saturated and/or mature markets (Bigdeli et al. 2018b; Gustafsson, Edvardsson, and Brax 2005). From these theoretical arguments and empirical evidence, the baseline hypothesis of this study emerges. By establishing this baseline hypothesis and demonstrating its legitimacy, the study can then conceptually build up with greater coherence to its subsequent premise (lifespan, explained in the next sub-section), which builds upon the following hypothesized relationship:

Hypothesis 1: Servitization is positively related to firm performance.

\section{The importance of product lifespan for servitization-based value-added}

The implementation of servitization strategies requires complex and profound organizational change. The conditions gauging the positive relationship between servitization and business performance remains a subject of debate in the literature (Kowalkowski et al. 2017). Empirical confirmations have been performed (Kohtamäki et al. 2013; Visnjic, Neely, and Jovanovic 2018), generally associated with the effect of contextual and specific internal variables that moderate the servitization-performance relationship (Bustinza et al. 2018). Li, Lin, Chen, and Ma (2015) as well as Szász, Demeter, Boer and Cheng (2017) tested whether the performance benefits of servitization for manufacturers only manifested themselves under specific levels of 
service intensity. Their conclusions follow the lines of the study by $\mathrm{Li}$, Liu, and Bustinza (2018), which confirms that more service-intensive manufacturing sectors tend to increase their international performance. Lafuente et al. (2017), in turn, conclude that sectors with greater collaboration with knowledge-intensive business service (KIBS) providers increase performance, while Vendrell-Herrero, Bustinza, and Opazo-Basaez (2020) provide evidence that this performance is greater in manufacturing firms that have undergone a digital transformation and made intensive use of information and communication technologies (Abou-Foul et al. 2020).

Further studies have examined the influence of internal variables. Belvedere, Grando, and Bielli (2013) test whether the ICTs implemented in firms positively moderate the relationship between servitization and performance; whereas Valtakoski and Witell (2018) confirm that experience is a positive force determining this relationship. The case study performed by Turunen and Toivonen (2011), in turn, shows that creating a service unit separate from the traditional organization of production in manufacturing firms increases performance (Fliess and Lexutt, 2019). On the other hand, an analysis of 102 manufacturing firms by Bustinza et al. (2015) determines that the contrasting nature of the goods and services produced entails distinctions in the impact that servitization can have on the level of performance achieved.

Absent, however, from these considerations into the link between servitization and performance is the durational factors of influence. If we take into consideration the intensifying transition towards solution business models that manufacturers have been undertaking (Fischer, Gebauer, and Fleish 2012) and the fact that relational longevity is a key component of successful solution delivery (Storbacka 2011), the lifespan of the offered service-augmented product is a likely influential variable. The increasing importance of servitization as a means of co-created personalized value-added would 
tend to imply product lifespan as a significant moderator of the servitizationperformance correlation for manufacturing firms. The fundamentals of the solutions business model dictate that customization requires dedicating resources, time and important upfront investments developing relationships and co-creating personalized solutions with buyers (Baden-Fuller and Morgan 2010). In fact, this is the main risk associated with adopting a solution business model. As such, profitability for firms adopting such a business model depends largely on the value and durability of relations with selected customer segments (Baden-Fuller and Morgan 2010). In-fact, product lifespan and consequent relational longevity is key in all of the four essential continuums identified by Storback et al. (2013) required for firms to properly transition towards a solution business model.

First, customer embeddedness is a key continuum in the transition to successful solution-base business (Storbacka et al. 2013). Customer embeddedness comes when exchange with customers becomes relational and long-term, where "the solution is developed, sold and delivered through long-term process 'with' the customer rather than ‘to’ the customer” (Storbacka et al. 2013, 707). Customer embeddedness is achieved when the unique business concerns of the customer are fully mastered allowing the manufacturer to supply a customer a specific value proposition (Anderson and Narus 1991). Understanding, developing and fulfilling such value propositions requires dynamic product-service systems that take time not only to elaborate, but also to deliver. The value delivery goes on much after the physical good is supplied, where the strategic importance of the servitization generated value-added increases with the potential lifespan of the solution sold.

Second, solution integratedness is the manufacturers' ability to longitudinally deliver servitized value-added, allowing them to supply more integrated solutions that 
enable better customization cost recovery (Johansson, Krishnamurthy, and Schlissberg 2003). Integrated solutions generate switching barriers for the customer who cannot unbundle easily the inter-dependent product-service system that creates value beyond the sum of its parts (Storbacka 2011). The increased levels of integratedness of longlifespan products allow the manufacturer to become a performance provider active within the customer's technical operations and long-term system optimization (Helander and Möller 2007). Contrary to when product-service commercial affairs are of a long lifespan, solution integratedness is not compatible with long-term customer relationships based on repeated purchase of a variety of short-lifespan products.

Third, organizational networkedness is a process harmonization across and within organizations that becomes ever more important with higher solution integratedness because buyer-supplier network becomes increasingly interdependent on each other (Bastl et al. 2012; Cheng, Chaudhuri, and Farooq 2016). This organizational networkedness is based on the importance of cooperation across the value chain to optimize the servitized value-added provided by increased solution delivery (Rapaccini and Visintin 2015; Zhou et al. 2020). As a manufacturer transitions through servitization to develop a longstanding solution business relationship that is genuinely customer oriented, the manufacturing firm "redefines itself from 'producer' to 'provider': where the provider does not necessarily produce everything it provides” (Storbacka et al. 2013, 708). The longevity of the product-service system around which this networkedness is built will largely dictate the symbiotic fit and value-generating potential of the resulting servitized solution delivery (Visnjic et al. 2017).

Fourth, servitizing manufacturers necessitate operational adaptiveness to viably transition towards a solution-based model whilst forgoing economies of scale and repetition in order to deliver rapid response to specific fluctuating customer 
requirements (Storbacka et al. 2013). In order to excel in solution business delivery with servitized product innovations, and achieve economic viability, it becomes important to be able to stretch-out the returns from the activity of integrating components and tailoring solutions to specific product-service systems through longer product lifespan (Storbacka 2011; Visnjic et al. 2017).

On the premise that servitization is an essential means by which manufacturers can transitions towards greater value-adding solution business modelling; where product lifespan is key for manufacturers to attain the customer embeddedness, solution integratedness, organizational networkedness, and operational adaptiveness necessary to optimize the servitization generated value-attainments, we formulate the following hypothesis:

Hypothesis 2: Product lifespan positively moderates the relationship between servitization and firm performance.

\section{Exploring the distinctive role of product lifespan along the service continuum}

Previous literature has often presented servitization as a continuum (Baines and Lightfoot 2013; Oliva and Kallenberg 2003). We argue that, in the context of servitized manufacturing firms, the performance-enhancement effect of product lifespan is especially relevant in late stages (more advanced) of the servitization journey.

For the sake of the argument, we focus on outcome base contracts, a particular type of high-intensive service popular in industrial buyer-seller relationships (Ng, Ding, and Yip, 2013). In an outcome-based contract, the producer sells the use of the product and not the property. The user pays a monthly/annual fee for the use of the product that includes, among other services, maintenance, upgrading and replacement when necessary. Any outcome-based service follows different development stages (solution planning, development, production, delivery, utilisation, and decomposition), being 
product-lifecycle a phase inside the service-integrated lifecycle model. Furthermore, advanced service-based solutions usually take the form of long-term contracts (Hou and Neely, 2018) that usually have a duration in between twenty and thirty years (Visnjic et al., 2017). In the present study, we consider this duration as the service lifespan. Outcome-based contracts frequently incorporates modernisation/upgrade product clauses for guaranteeing the optimal agreed upon outcome between provider and user. Considering that product modernisation requires additional planning, development, production, and distribution costs, short product lifespan could be considered a plausible hidden cost variable in this kind of contracts. Moreover, innovative products with shorter lifecycles require high technological upgrade and are characterized for being more fashion oriented (Lee, 2002), opening space for different commercial and operational risks (Hou and Neely, 2018).

Formulating this function, let us define $t_{s}$ as service lifespan and $t_{p}$ as product lifespan. As a general norm, we can consider that since outcome base contracts contain product upgrading and replacement, service lifespan is equal or larger than product lifespan $\left(t_{s} \geq t_{p}\right)$. Considering this property, we can analyse the ratio $t_{s} / t_{p}$, which will take value one when product lifespan equals service lifespan (no replacement). When the ratio is larger than one there will be at least one replacement, and more generally, when the ratio is larger than $n$ there will be at least $n$ replacements. In this framework, if we assume $t_{s}$ to be between twenty and thirty years, selling products with long lifespan reduces the ratio $t_{s} / t_{p}$. As such, having a smaller ratio translates to a number of advantages that might increase the value obtained from offering solutions:

- By having a small ratio $t_{s} / t_{p}$, the total upgrading and replacement cost diminishes significantly. This is an important component that impacts the capacity of the firm to extract value from servitization. 
- In an industrial setting, moral hazard occurs when the buyer has an incentive to increase its exposure to risk (e.g. incorrect use of the product) because it does not bear the full costs of that risk (e.g. buyer does not own the product) (e.g. Hypko, Tilebein \& Gleich, 2010). Moral hazard will be more predominant when the buyer knows that there are multiple opportunities of product upgrading/replacement within the service contract. This means that firms selling products with shorter lifespan will need to invest more resources in monitoring buyer's behaviour, which negatively affects the potential for value generation.

- The buyer can have an opportunistic behaviour each time there is a product replacement (e.g. Richter, Sadek \& Steven, 2010). For instance, the buyer could take advantage of the product replacement to find a new supplier that cancels the contract, or at least opens the possibility of renegotiating the terms of the contract. This means that firms selling products with shorter lifespan will need to discount future renegotiating costs at the time of setting up the outcome base contracts, which diminishes the potential for value generation.

In sum, we hypothesize that product lifespan has a particularly important moderating role in more advanced stages of servitization.

Hypothesis 3: The moderation effect of product lifespan on the relationship between servitization and firm performance is stronger in advanced stages of servitization.

\section{Methodology}

\section{Description of the database}

The empirical study supporting the research uses an in-depth survey of practices performed by manufacturing firms, which includes specific questions about servitization and business performance. The questionnaire was developed through an 
alliance with two corporate partners; one, a specialist in service management solutions, and the other, a global consulting firm. The first partner had a catalogue of 7,000 multinational production firms that innovate their business models through services associated with the product and that have annual revenues of over a billion dollars. This group of multinational firms covers a selection of leading firms in the servitization domain that could be considered a representative set of worldwide multinational firms that servitize. The management solution partner used an advisory council composed of experts outside the industry to validate both the questionnaire and the study sample before questionnaire administration. The global consulting firm was responsible for administering the questionnaire.

The goal was to produce a statistically representative sample of the population. The sample size was determined using the Gauss distribution with a confidence level of 95\%. This procedure generated a target sample size of at least 365 production multinationals. ${ }^{1}$ To ensure that no responses were duplicated, respondents received a single password by email. The sampled firms were contacted periodically by email and telephone during the months of November and December, 2013, until 370 firms had completed the survey online, five more than the target sample size. Eighteen responses were incomplete and 51 firms operating in the ‘cargo airlines’ sector were excluded from the sample because there is no tangible product ascribed to them, leaving a total of 301 usable surveys. The respondents chosen were individuals in charge of one or more cost or benefit centres in the business for their company's services.

1. $n=\frac{N * Z^{2} * p *(1-p)}{(N-1) * e^{2}+Z^{2} * p *(1-p)}$, where $\mathrm{n}$ is the target sample size, $\mathrm{N}$ refers to population size $(\mathrm{N}=7,000)$, $Z=+/-1.96$ (confidence level of 95\%), e the error margin (e $=5 \%$ ), and $p$ a realistic estimation of desired probability $(\mathrm{p}=0.50)$. 


\section{Description of the dependent and independent variables}

The dependent variable is Firm performance. The variable is an adaptation of the constructed variable used by Bustinza et al. (2019), which includes items on distal (i.e. organizational performance) and proximal (i.e. common business performance metrics) outcomes. In particular, this scale consists of four items measured with a 5-point Likert scale $(1$ = significantly negative effect, 5 = significantly positive effect $)$ that address the following subjects: a) competitive differentiation, b) change in profit level, c) new income sources and d) customer satisfaction (see Table 1 for a more elaborate item description). These questions enable us to evaluate the change in the competitive performance of the firms involved in introducing a product-service portfolio. The principal components' analysis with Varimax rotation produces values of $\mathrm{KMO}=$ 0.821 , and Bartlett's sphericity test yields $x^{2}=1453.675(p=0.000)$, with a variance extracted of $57.73 \%$. Analysis of the scale’s internal consistency-measured using the Alpha Cronbach $(\alpha=0.859)$, total variance extracted (57.45\%) and composite reliability (0.843) — all provide values sufficient to validate reliability.

Our independent variable is Servitization. The variable follows current approaches for measuring servitization intensity (see Calabrese et al., 2019). The specific operationalization of the variable was adopted from the study by VendrellHerrero et al. (2020). ${ }^{2}$ The variable is composed of four items that focus on measuring the development of services as well as closeness and depth of customer-centric links. Specifically, they include the following four items, all of which are measured with a 5point Likert scale (1 = Completely disagree, 5 = Completely agree): new productsservices provided, level of updates available, positive valuation and customer comments

\footnotetext{
2 The original construct formed by using these items was named as product-service innovation, but previous research has acknowledged that the terms servitization and product-service innovation can be used interchangeably (Bustinza et al. 2018).
} 
for improvement, and alignment in development of products and services (see Table 1 for a more elaborate item description). Through principal components analysis with Varimax rotation— $\mathrm{KMO}=0.834$, and Bartlett's sphericity test $\mathrm{x}^{2}=4.764 .332(\mathrm{p}=$ 0.000) — the items considered enable us to explain $61.45 \%$ of the variance. The items are statistically significant ( $t>1.96$, confidence level 95\%), the factor loadings are above the recommended level of 0.4 and the individual reliabilities are above 0.6 . The four items correlate positively, and the scale's internal consistency-measured through the Alpha Cronbach ( $\alpha=0.814)$-is suitable. In addition, the total variance extracted (56.87\%) and composite reliability (0.802) guarantee its reliability as a scale. Once the scale's validity is confirmed (Hair et al. 2001), the computed linear value is used to operationalize the servitization variable. The resulting continuous variable can be interpreted as an indicator. A firm can therefore be considered to achieve a level of innovation in the product's service above the sample average whenever the value of service for the product imputed to that specific firm is positive.

Table 1. Items for dependent and independent variable

Please indicate the extent to which you disagree/agree with the following statements using a 5-point scale where 1 = "completely disagree" and $5=$ "completely agree"

\begin{tabular}{|c|c|l|}
\hline ID & ITEM & \multicolumn{1}{|c|}{ QUESTION } \\
\hline Dependent variable: Firm performance \\
\hline PERF1 & $\begin{array}{c}\text { Competitive } \\
\text { Differentiation }\end{array}$ & $\begin{array}{l}\text { Regarding the effect on firm differentiation. Your product-service } \\
\text { portfolio generates a competitive advantage in your market. }\end{array}$ \\
\hline PERF2 & $\begin{array}{l}\text { Increased } \\
\text { Profitability }\end{array}$ & $\begin{array}{l}\text { Regarding firm profitability. Your business has an increased } \\
\text { profitability due to reduced cost of services and/or greater service } \\
\text { efficiencies. }\end{array}$ \\
\hline PERF3 & $\begin{array}{l}\text { New Revenue } \\
\text { Streams }\end{array}$ & $\begin{array}{l}\text { Regarding the generation of new revenue streams. By offering value- } \\
\text { added services and/or outcome-based contracts your business has } \\
\text { obtained new revenue streams. }\end{array}$ \\
\hline PERF4 & $\begin{array}{l}\text { Customer } \\
\text { Satisfaction }\end{array}$ & $\begin{array}{l}\text { Regarding customer satisfaction. By offering value-added services } \\
\text { and/or outcome-based contracts the business has increased customer } \\
\text { engagement and satisfaction. }\end{array}$ \\
\hline Independent variable: Servitization \\
\hline SERV1 & $\begin{array}{c}\text { Product } \\
\text { Innovation }\end{array}$ & $\begin{array}{l}\text { Regarding your new product introductions (before product release). } \\
\text { Engineering and service leadership are equitable collaborators in } \\
\text { defining and delivering new solutions to meet customer-driven }\end{array}$ \\
\hline
\end{tabular}




\begin{tabular}{|c|c|l|}
\hline SERV2 & $\begin{array}{c}\text { Updated } \\
\text { Product } \\
\text { Lifecycle }\end{array}$ & $\begin{array}{l}\text { Regarding your product-lifecycle related updates/changes. The impact } \\
\text { of service-proposed engineering changes is evaluated, approved and } \\
\text { implemented through each phase of the offerings upgrading process. }\end{array}$ \\
\hline SERV 3 & $\begin{array}{c}\text { Service } \\
\text { Feedback and } \\
\text { Analytics }\end{array}$ & $\begin{array}{l}\text { Regarding your service feedback and analytics. Engineering and } \\
\text { service leadership are equitable collaborators in capturing and } \\
\text { analyzing product and service information for continuous } \\
\text { improvement; and hence, they foster the design of new product and } \\
\text { service offerings. }\end{array}$ \\
\hline SERV 4 & $\begin{array}{c}\text { Product-service } \\
\text { Alignment }\end{array}$ & $\begin{array}{l}\text { Regarding your collaboration tools usage (after product release). } \\
\text { Product-Lifecycle Management (PLM) and Service-Lifecycle } \\
\text { Management (SLM) processes and systems are highly integrated with } \\
\text { each other. }\end{array}$ \\
\hline
\end{tabular}

\section{Description of the moderating variable}

The moderating variable is product lifespan. In our study we consider that firms operate in a single industry. Despite the possibility that firms can sell multiple products, the product range for the firm will have similar product lifespan as they fall within the same general industry. ${ }^{3}$ With this set up, we can use an industry-level moderating variable (see Bustinza et al., 2019; Foster et al., 2016; Kim and Ployhart, 2018).

The sample analysed includes firms belonging to six industries, distributed uniformly such that each sector was represented by approximately 50 firms. Prior work has documented the relatively greater proclivity of the selected industries to engage in servitization processes (e.g. Bustinza et al. 2019; Rabetino et al. 2018). Table 2 characterizes the sectors in terms of the mean lifespan of their most representative products according to the LiVES database, collected by the Japanese National Institute for Environmental Studies. LiVES forms part of a project unique in the world that seeks

\footnotetext{
${ }^{3}$ Whilst an iPhone and a MacBook (two feature products of Apple) do not have exactly the same product lifespan, they both will have a relatively short product lifespan. Rolls Royce produces a wide range of turbines, from civil aerospace to naval defense. These turbines will have different sizes and propulsion power, but their durability will be similar (long product lifespan).
} 
to identify the lifespan of products (Murakami et al. 2010; Oguchi et al. 2010). The data is available free of charge online at http://www.nies.go.jp/lifespan.

Table 2. Industry and product lifespan

\begin{tabular}{|c|c|c|c|c|c|}
\hline \multicolumn{6}{|c|}{$\begin{array}{l}\text { INDUSTRY TYPE } \\
\end{array}$} \\
\hline \multicolumn{2}{|c|}{ Long product lifespan } & \multicolumn{2}{|c|}{ Middle product lifespan } & \multicolumn{2}{|c|}{ Short product lifespan } \\
\hline $\begin{array}{l}\text { Industry and } \\
\text { products }\end{array}$ & $\begin{array}{l}\text { Mean } \\
\text { lifespan } \\
\text { (Years) }\end{array}$ & $\begin{array}{l}\text { Industry and } \\
\text { products }\end{array}$ & $\begin{array}{c}\text { Mean } \\
\text { lifespan } \\
\text { (Years) }\end{array}$ & $\begin{array}{l}\text { Mean } \\
\text { lifespan } \\
\text { (Years) }\end{array}$ & $\begin{array}{c}\text { Mean } \\
\text { lifespan } \\
\text { (Years) }\end{array}$ \\
\hline $\begin{array}{l}\text { Automotive and } \\
\text { Transportation } \\
\text { (48 firms) }\end{array}$ & 24 & $\begin{array}{l}\text { Heavy and } \\
\text { Industrial } \\
\text { Equipment } \\
\text { (52 firms) }\end{array}$ & 16.5 & $\begin{array}{l}\text { White Goods } \\
\text { Manufacturing } \\
\text { (52 firms) }\end{array}$ & 10.6 \\
\hline Rail cars & 34.7 & $\begin{array}{l}\text { Transformers } \\
\text { and reactors }\end{array}$ & 22.7 & Washing machine & 12 \\
\hline $\begin{array}{l}\text { Elevators and } \\
\text { escalators }\end{array}$ & 31.5 & $\begin{array}{l}\text { Industrial } \\
\text { robots }\end{array}$ & 17.3 & Electric Cooker & 12 \\
\hline Cargo ships & 20 & $\begin{array}{l}\text { Engraving } \\
\text { machinery }\end{array}$ & 15.3 & Refrigerators & 11.7 \\
\hline $\begin{array}{l}\text { Platform trucks } \\
\text { (trailers) }\end{array}$ & 17.6 & Machine tools & 14 & Drying machines & 9 \\
\hline $\begin{array}{l}\text { Motor coaches for } \\
\text { passengers }\end{array}$ & 16.3 & Excavators & 13.1 & Vacuum Cleaners & 8.3 \\
\hline $\begin{array}{l}\text { Aerospace and } \\
\text { Defence } \\
\text { (48 firms) }\end{array}$ & 23.2 & $\begin{array}{l}\text { Medical } \\
\text { Devices and } \\
\text { Equipment } \\
\text { (50 firms) }\end{array}$ & 13.1 & $\begin{array}{l}\text { Electronics and } \\
\text { High-Tech } \\
\text { Equipment } \\
\text { (51 firms) }\end{array}$ & 9.7 \\
\hline Defence ships & 26.8 & $\begin{array}{l}\text { Medical } \\
\text { instruments }\end{array}$ & 12.4 & Air conditioners & 13.1 \\
\hline \multirow[t]{4}{*}{ Engines and turbines } & 19.6 & $\begin{array}{l}\text { Measurement } \\
\text { instruments }\end{array}$ & 13.7 & $\begin{array}{l}\text { Electric lighting } \\
\text { fixtures and devices }\end{array}$ & 12.5 \\
\hline & & & & $\begin{array}{l}\text { Semiconductor- } \\
\text { making equipment }\end{array}$ & 9.4 \\
\hline & & & & Printers & 7.1 \\
\hline & & & & Computers & 6.5 \\
\hline
\end{tabular}

Source: http://www.nies.go.jp/lifespan - We take the most recent figure for each product category indicated.

Even with the large selection of products in the LiVES database, not all are directly related to the sectors analysed in this study. Based on the products available in LiVES, we chose a minimum of two and a maximum of five representative products from each sector to enable direct visualization of the mean lifespan of the products in 
each industry. ${ }^{4}$ Further to the continuous industry-level measure, we differentiate between sectors qualitatively. The categories considered were:

- Long lifespan (LL): ‘aerospace and defence’ as well as ‘automotive and transportation' — both characterized by their small number of supplied products, all of which have great economic value and a long lifespan (23-24 years). 96 firms belong to this category.

- Middle Lifespan (ML): Industrial and medical equipment, which are characterized by an intermediate volume and product lifespan (14-15 years). 102 firms belong to this group.

- Short Lifespan (SL): Electronic equipment and home appliances, which commercialize a higher volume of products but with a single value and considerably shorter lifespan (9-10 years). 103 firms belong to this category.

\section{Description of the control variables}

In addition to industry, our study controls for firm size and home world region.

Firm size: Although all firms in the sample have, by design, a yearly billing volume of over a billion dollars, there is significant internal size heterogeneity. To control for this characteristic, the sample was divided into four categories according to yearly billing volumes: i. firms whose yearly billing volume ranges between 1 to 4.9 billion dollars, ii. firms whose yearly billing volume is between 5 to 9.9 billion dollars, iii. firms whose yearly billing volume ranges between 10 to 19.9 billion dollars, and iv. firms whose yearly billing volume is over 20 billion dollars. As Figure 1 shows, the size distribution reveals some noteworthy differences in type of product (LL vs. ML vs. SL). The most

4 For those industries with more than five products available, the computed average industry lifespan was compared with other bundles of products, and average industry lifespan remains similar for all industries. 
significant difference lies in the greater percentage of SL firms in the smallest class size ( $29 \%$ vs. $23 \%$ vs. $35 \%$ ), the greater percentage of LL firms in the size category of 5 to 9.9 billion annual billing volume (35\% vs. $24 \%$ vs. $21 \%$ ), and the greater percentage of ML firms in the largest class size (5\% vs. $17 \%$ vs. $9 \%$ ). If we average the categorical variable, in which " 1 " is the value for the smallest group of firms and " 4 " the value for the largest, the average value for ML firms (2.45) is statistically larger than the average for LL (2.11) and SL (2.17). The difference between LL and SL is not statistically significant.
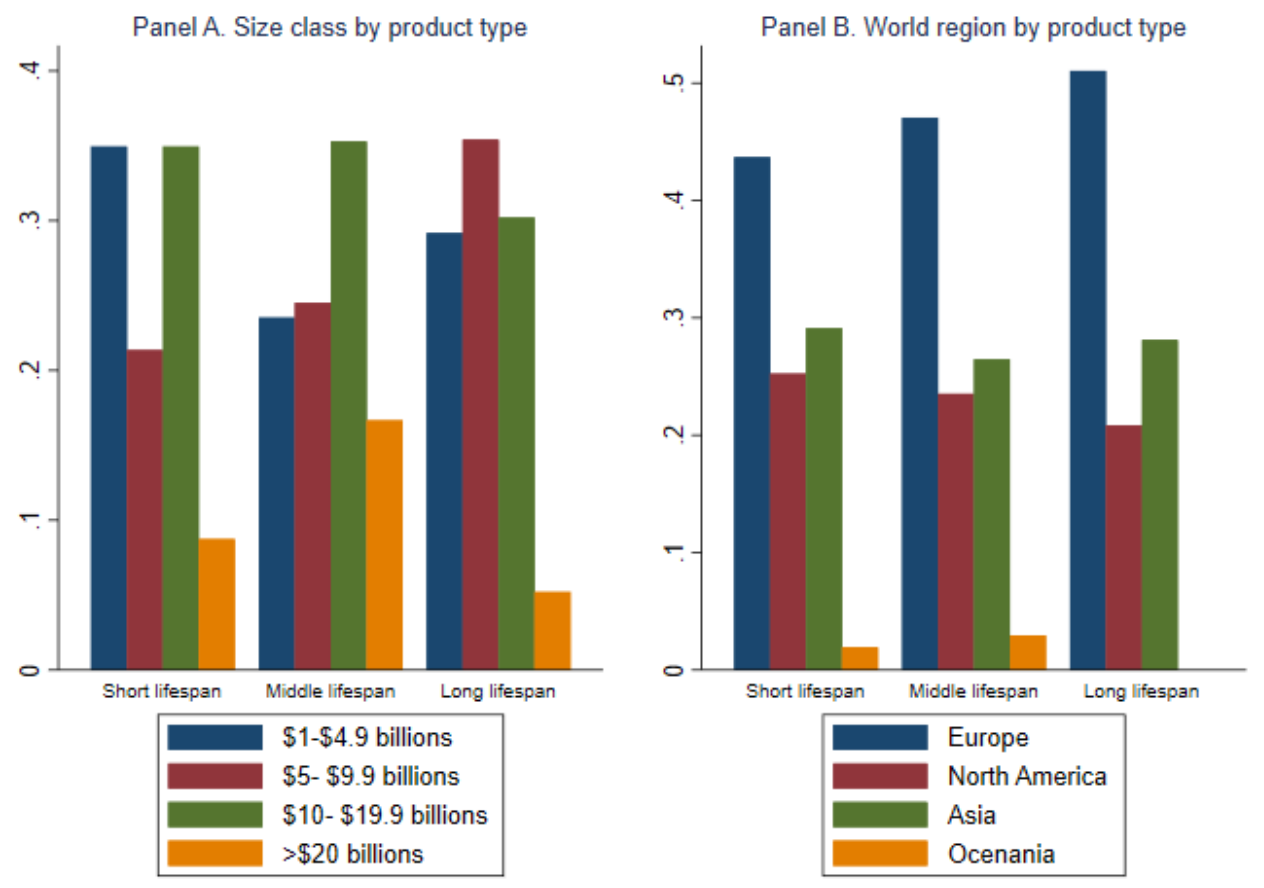

Figure 1. Distribution of short, middle and long product lifespan in relation to class size and world region

Home world region: The production multinationals analysed have their headquarters situated across many different points of the planet. To simplify, we classified the 
location according to four regions ${ }^{5}$ : Europe, North America, Asia and Oceania. As Figure 1 shows, the distribution is approximately the same for the three kinds of firms, with some noteworthy differences. 51\% of firms with LL products are European, and the presence of European firms falls to $47 \%$ and $43 \%$ in firms with ML and SL products respectively. This difference can be explained primarily by a higher percentage of firms with SL and ML products in North America (20\%[LL] vs. 23\%[ML] vs. 25\%[SL]).

The representation of Asian firms is the same in the three samples (around 27-28\%). The sample for Oceania contains five firms, two belonging to the group of firms with SL products and the other three sell ML products.

\section{Tests for non-response and common method bias}

To assess non-response bias (NRB), we compared early and late respondents (first and last decile) for the dependent and the independent variables through a $t$-test (Armstrong and Overton 1977). Statistical differences between early and late respondents were not found ( $p$-value $>0.1)$. In addition, during the data collection process, our industry partner compared the number of employees among responding and non-responding firms. No significant differences were reported; meaning that there is no significant difference between respondents and non-respondents in terms of number of employees ( $p$-value $>0.1)$. Overall, NRB is absent in our sample.

Common method bias (CMB) can arise when construct variability is caused by the design of the survey instrument rather than respondents’ opinion, a common limitation of surveys that needs to be further examined. Following Chang, Van Witteloostuijn, and Eden (2010), we took two ex-ante precautions against CMB. First,

5. The European countries are Belgium, France, Germany, Holland, Denmark, Finland, Italy, Norway, Sweden and Russia. North American countries are Canada and the United States. Asian countries are China, Japan, Singapore and Hong Kong. Finally, the country representing Oceania is Australia. 
the moderating variable is objectivized and come from an independent source (LiVES). Second, an effort was made to ensure that respondents were familiar with firm strategy (45.9\% of respondents were directors, $43.2 \%$ held a corporate-level position, and $11.9 \%$ were executive vice-presidents). We also conducted standard validity assessment through the Unmeasured Latent Method Factor (ULMF) procedure ${ }^{6}$ and have implemented the CFA marker technique ${ }^{7}$. None of these approaches indicated the existence of CMB. From these results we can strongly conclude that NRB and CMB do not negatively hinder the study’s estimations.

\section{Results}

\section{Testing direct and moderation effects (Hypotheses 1 and 2)}

To assess the proposed hypotheses, we test the baseline model presented in Equation (1) through ordinary least squares (OLS).

$$
\operatorname{Perf}_{i}=\alpha_{0}+\alpha_{1} \operatorname{Serv}_{i}+\alpha_{2} \text { Lifespan }_{i}+\alpha_{3} \operatorname{Serv} * \operatorname{Lifespan}_{i}+\vartheta_{s}+\vartheta_{r}+\vartheta_{I}+\varepsilon_{i}
$$

Where Perf is the business performance, Serv the degree of servitization, and Lifespan the continuous measure of product lifespan at industry level. In accordance with Hypothesis 1 , we expect $\alpha_{1}$ to be positive and significant, and to support Hypothesis 2 we expect $\alpha_{3}$ to be positive and significant. $\vartheta_{s}$ are size dummies, $\vartheta_{r}$ are

\footnotetext{
${ }^{6}$ ULMF is an ex-post CMB test consisting on a confirmatory factor analysis (CFA) in which all variables of interest in the study (dependent, independent, and moderating variables) were loaded onto a common method factor (Min, Park, and Kim 2016). The fit of the resulting model was poor (TLI = 0.633 and CFI $=0.768$, acceptance range $>0.900 ;$ RMSEA $=0.102$, acceptance range 0.050-0.080).

${ }^{7}$ CFA marker technique estimates CMB as a function of a considered marker (Richardson, Simmering, and Sturman 2009). In our case, the second smallest positive correlation among the manifest variables - and the substantive model. Following Simmering et al. (2015), we calculate for a 95\% confidence interval around each uncorrected model relationship. Because the corrected estimates for the CFA marker fall inside the set confidence intervals of the original estimates, no meaningful differences that could lead to presume CMB was detected.
} 
regional dummies, and $\vartheta_{I}$ are industry dummies. The specific aim for the inclusion of these dummies is to control for factors related to size, geography and industry through the introduction of their corresponding fixed effects. The inclusion of size, country and industry dummies significantly increase the model’s explanatory capacity (R-squared increases from $3 \%$ to $13 \%$ when these effects are introduced). ${ }^{8} \varepsilon_{i}$ is the error term. The linear regression analysis also involves a singular type of assumption regarding standard errors. Our case assumes that errors are normally distributed but makes no assumption about their variance and therefore estimates Huber-White robust errors (Imbens and Kolesar 2016).

Table 3 reports the results with a hierarchical approach. Column 1 only introduces the explanatory variables; level of servitization and the continuous measure of lifespan. Column 2 repeats these same variables but controls for the fixed effects of region, size and industry. These models test the validity of Hypothesis 1 -that is, whether firms that servitize have greater performance. Although the significance level decreases from $1 \%$ to $5 \%$ after controlling for fixed effects, the servitization parameter $\left(\alpha_{1}\right)$ is positive and significant in both models. This result permits us to support our Hypothesis 1 that states that Servitization is positively related to firm performance. Table 3. OLS analyses with Product lifespan being a continuous variable

\begin{tabular}{lcccc}
\hline \hline & $(1)$ & $(2)$ & $(3)$ & $(4)$ \\
Variable & OLS & OLS & OLS & OLS \\
\hline Servitization (SERV) & $0.163^{* * *}$ & $0.123^{* *}$ & -0.251 & -0.219 \\
& $(0.0545)$ & $(0.0577)$ & $(0.159)$ & $(0.409)$ \\
Lifespan (years) & -0.00775 & -0.0140 & -0.0113 & -0.123 \\
& $(0.0125)$ & $(0.0185)$ & $(0.0180)$ & $(0.0821)$ \\
\hline SERV*Lifespan & & & $0.0239^{* *}-$
\end{tabular}

8. We use an industry-level measure for product lifespan. This is compatible with industry-fixed effects in the specification (e.g. Müller, Fay and vom Brocke 2018). Industry-fixed effects account for sectorspecific level of performance, whereas the industry-level measure of product lifespan accounts for the additional profit of increasing the average product lifespan in the industry. 
Low-intensity \& SL

(0.0103)

Medium-intensity \& SL

0.0539

(0.0403)

$-0.0172$

(0.0382)

High intensity \& SL

0.0629

(0.0416)

Low-intensity \& LL

0.0185

(0.0273)

Medium-intensity \& LL

0.0315

(0.0210)

High-intensity \& LL

(0.0259)

\begin{tabular}{lcccc}
\hline Constant & 0.105 & 0.00689 & -0.0612 & 0.347 \\
& $(0.198)$ & $(0.352)$ & $(0.342)$ & $(1.170)$ \\
\hline Size FE & NO & YES & YES & YES \\
Region FE & NO & YES & YES & YES \\
Industry FE & NO & YES & YES & YES \\
Service type FE & NO & NO & NO & YES \\
\hline$N$ & 301 & 301 & 301 & 301 \\
$R^{2}$ & 0.030 & 0.110 & 0.129 & 0.174 \\
$\Delta$ R-squared & & +0.080 & +0.019 & +0.045 \\
\hline \hline
\end{tabular}

Dep. var.: Firm performance. Robust standard errors are in parentheses. *** $\mathrm{p}<0.01,{ }^{* *} \mathrm{p}<0.05,{ }^{*} \mathrm{p}<0.1$

We then perform moderation analysis for the lifespan measured by product lifespan. Column 3 introduces the interaction effect between servitization and product lifespan. The coefficient of the interaction term capturing the moderating effect of product lifespan in the servitization-performance relationship $\left(\alpha_{3}\right)$ is used to test Hypothesis 2. The coefficient is positive and statistically significant at 5\%. This result is in line with our Hypothesis 2 that proposes that Product lifespan positively moderates the relationship between servitization and firm performance.

In order to provide a graphical visualization of this analysis we followed previous research analysing the interaction effect of two continuous variables (Press et al. 2007; Vendrell-Herrero, Darko, and Vaillant 2020). That is, Figure 2 exhibits a contour plot based on the results reported in column 3 of Table 3. The figure shows a two-dimension graph where different combinations of servitization (Y-axis) and product lifespan (X-axis) yield different predicted performance levels, which are represented in 
the colour-scale of the figure. From the contour plot, we observe that firms selling products with shorter product lifespan do not benefit from servitization strategies. Additionally, servitization seems essential for enhanced performance in businesses offering products with longer lifespan.

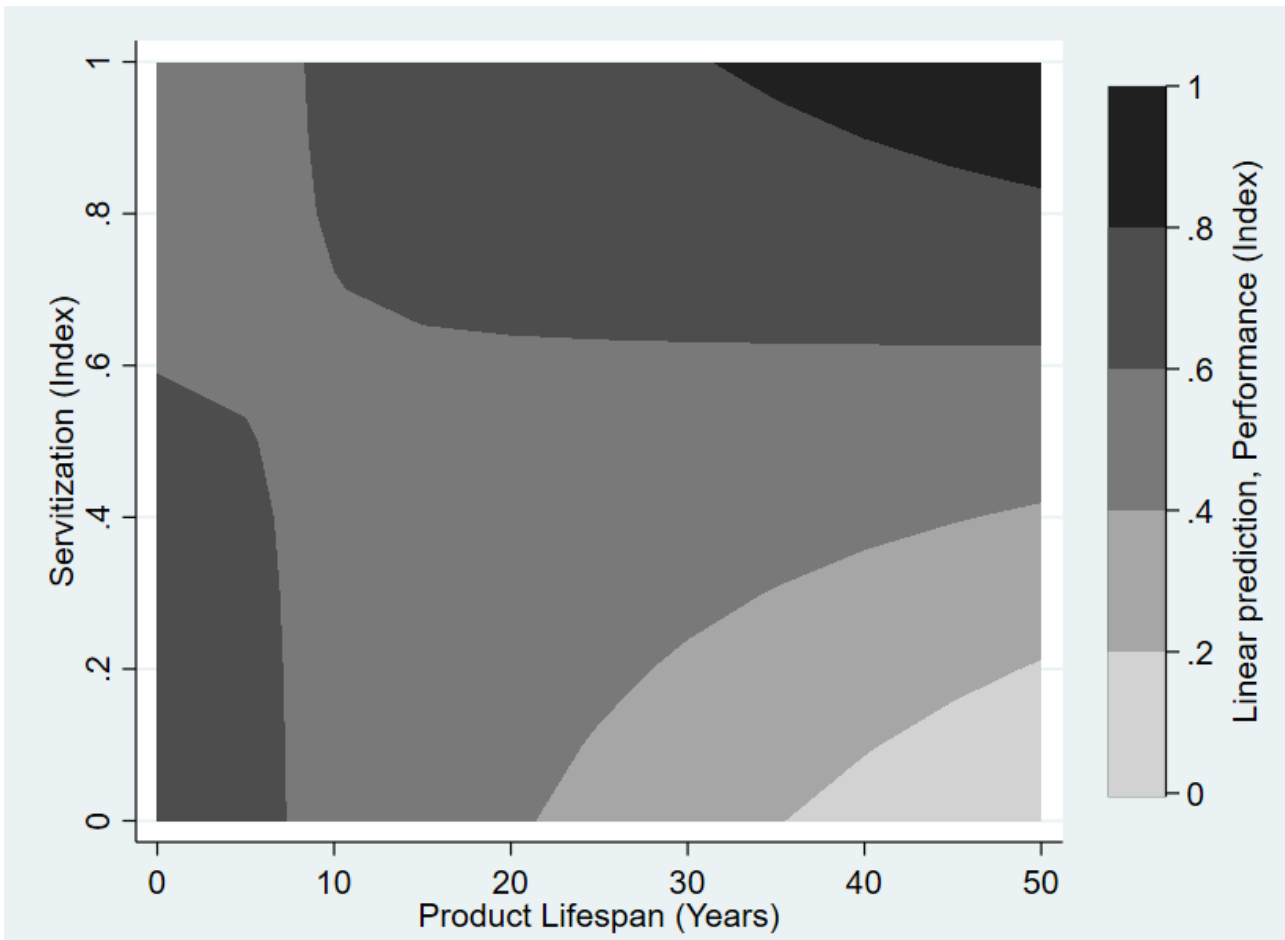

Note: Values for our dependent and independent variables have been indexed in this plot to facilitate the interpretation. Both values have been transformed using the following formula: Index = (firm value sample minimum)/(sample maximum - sample minimum)

Figure 2. The relationship between servitization and performance along different product lifespan

The study's method has so far quantified product lifespan at industry level. Because this measure might not entirely reflect the actual product lifespan at firm level, we proceed to solve this issue by splitting the sample in firms that unequivocally have short and large product lifespan. We dichotomize the sample by dropping those firms in industries with middle lifespan and construct a binary variable that takes value " 1 ” when the firm belongs to a sector that has long product lifespan (96 firms) and “0” when the firm 
belongs to a sector that has short product lifespan (103 firms). Based on this sample we proceed to report two different analysis that corroborate our results: (a) reproduce the linear regression with adjusted sample and measure of product lifespan, and $(b)$ test our hypothesis through structural equation modelling.

(a) Linear regression with adjusted sample and measure of product lifespan: Table 4 replicates the analysis performed in Table 2 by using the binary measure of product lifespan. According to Columns 1 and 2 the servitization parameter $\left(\alpha_{1}\right)$ is positive and significant in both models, although the significance level decreases from $5 \%$ to $10 \%$ after controlling for regional, industry and class size dummies. This result permits us to support our Hypothesis 1. According to Column 3 the interactive term between long product lifespan and servitization is positive and significant at 5\%, enabling to support our Hypothesis 2.

Table 4. OLS analysis with Product lifespan being a dummy variable

\begin{tabular}{|c|c|c|c|c|}
\hline & $\begin{array}{l}(1) \\
\text { OLS }\end{array}$ & $\begin{array}{l}(2) \\
\text { OLS }\end{array}$ & $\begin{array}{c}(3) \\
\text { OLS }\end{array}$ & $\begin{array}{c}(4) \\
\text { OLS }\end{array}$ \\
\hline Servitization (SERV) & $\begin{array}{l}0.168 * * \\
(0.0664)\end{array}$ & $\begin{array}{c}0.120^{*} \\
(0.0718)\end{array}$ & $\begin{array}{c}-0.0399 \\
(0.0824)\end{array}$ & $\begin{array}{l}-0.794 \\
(0.535)\end{array}$ \\
\hline Long lifespan (LL) & $\begin{array}{l}-0.156 \\
(0.170)\end{array}$ & $\begin{array}{r}-0.0637 \\
(0.228)\end{array}$ & $\begin{array}{r}-0.0555 \\
(0.226)\end{array}$ & $\begin{array}{l}-2.079 \\
(1.579)\end{array}$ \\
\hline SERV*LL & & & $\begin{array}{l}0.339 * * \\
(0.143)\end{array}$ & \\
\hline Low-intensity \& SL & & & & $\begin{array}{l}1.048^{*} \\
(0.623)\end{array}$ \\
\hline Medium-intensity \& SL & & & & $\begin{array}{c}0.238 \\
(0.588)\end{array}$ \\
\hline High intensity \& SL & & & & $\begin{array}{c}0.803 \\
(0.862)\end{array}$ \\
\hline Medium-intensity \& LL & & & & $\begin{array}{c}1.299 * * \\
(0.583)\end{array}$ \\
\hline High-intensity \& LL & & & & $\begin{array}{c}2.333 * * * \\
(0.884)\end{array}$ \\
\hline Constant & $\begin{array}{l}0.0807 \\
(0.102)\end{array}$ & $\begin{array}{c}-0.334 * \\
(0.194)\end{array}$ & $\begin{array}{c}-0.412 * * \\
(0.204)\end{array}$ & $\begin{array}{c}1.067 \\
(1.150)\end{array}$ \\
\hline Size FE & NO & YES & YES & YES \\
\hline Region FE & NO & YES & YES & YES \\
\hline Industry FE & NO & YES & YES & YES \\
\hline Service type FE & NO & $\mathrm{NO}$ & NO & YES \\
\hline Observations & 199 & 199 & 199 & 199 \\
\hline
\end{tabular}




\begin{tabular}{|c|c|c|c|c|}
\hline $\begin{array}{l}\mathrm{R} \text {-squared } \\
\Delta \mathrm{R} \text {-squared }\end{array}$ & 0.03 & $\begin{array}{c}0.122 \\
+0.088\end{array}$ & $\begin{array}{c}0.152 \\
+0.030\end{array}$ & $\begin{array}{c}0.199 \\
+0.047\end{array}$ \\
\hline
\end{tabular}

Dep. var.: Firm performance. Robust standard errors are in parentheses.

*** $\mathrm{p}<0.01, * * \mathrm{p}<0.05,{ }^{*} \mathrm{p}<0.1$

(b) Structural equation modelling: Our study employs latent constructs (servitization and performance). The use of these variables for analytical purposes is common in relevant business literature. However, these variables have certain properties that require adjustments for generating accurate estimations (Acock 2013). To correct for potential bias and ensure greater reliability in our results, we also modelled the relationship between servitization and performance through Structural Equation Modelling (SEM). Keep in mind that, contrary to the regression models estimated in the previous section (Table 3), SEM does not account for fixed effects or other control variables.

The role of product lifespan as moderator of the relationship between servitization and firm performance (see Figure 3) is analysed through SEM. The model is estimated using Stata software (Acock 2013), where the results of the overall goodness of fit indicators are found to be satisfactory -Chi-square likelihood: $\chi^{2}(19)=$ $22.60(p=0.26>0.01) ; R M S E A=0.07 ; S R M R=0.049 ; C F I=0.98 ; R^{2}=0.62 ;$ $\rho_{\text {reliability }}=0.83$. We find a positive effect of Servitization on Firm performance $\beta_{\text {Serv } \rightarrow F P e r f}=0.38(t=2.65 ; p<0.01)$, supporting Hypothesis 1 . After that, we analyse the moderating role of lifespan. In doing so, median multi-group analysis of two models (Long lifespan and Short lifespan respectively) was run. $\chi^{2}$ difference test displaying probability distribution function (degrees of freedom difference, $\chi^{2}$ difference)- shows significant differences between the models, verifying that product lifespan moderate the relationship between servitization and firm performance. Figure 3 shows that the parameter for Long Lifespan increased from $\beta_{\text {Serv } \rightarrow \text { FPerf }}=$ 
$0.38(t=2.65 ; p<0.01)$ to $\beta_{\text {ServLongLife } \rightarrow \text { FPerf }}=0.59(t=3.42 ; p<0.01)$. These results indicate that the effect of servitization on firm performance is significantly higher for long lifespan products thus supporting Hypothesis 2.

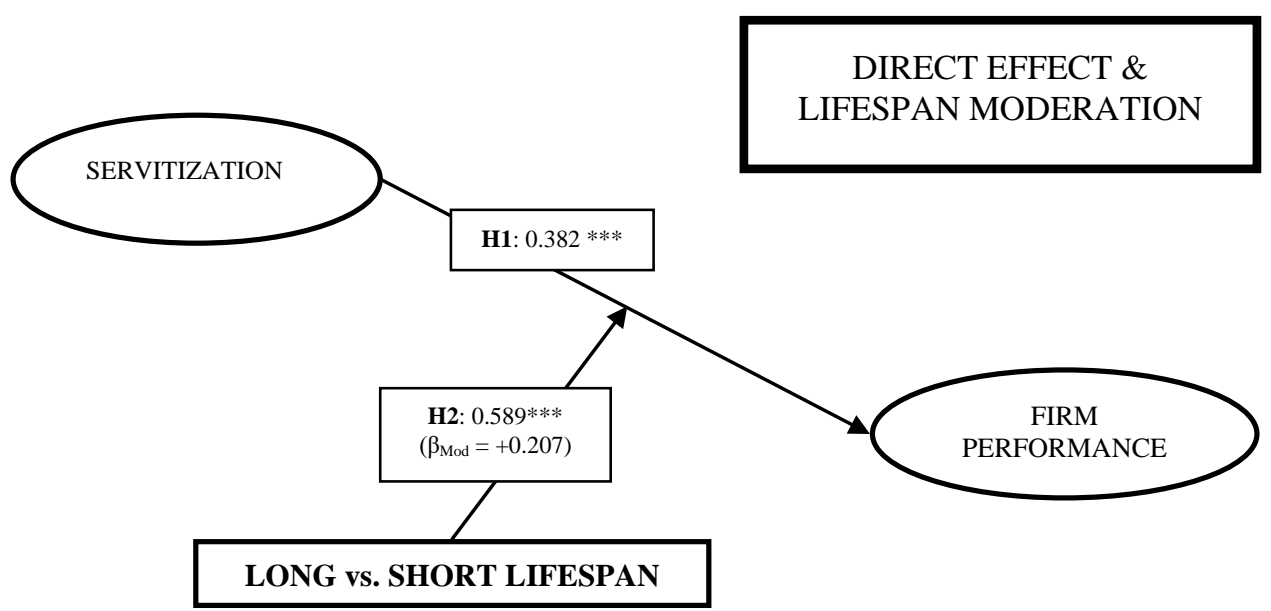

Figure 3. SEM analysis of servitization and firm performance considering lifespan moderation

\section{Testing the moderation effect along the service continuum (Hypothesis 3)}

By construction of the sample, all analysed firms are servitized, although at different intensity levels, represented by linearly predicted factor scores. By construction, factor scores are standardized to a mean of zero and a standard deviation equal to the squared multiple correlation between factors (DiStefano, Zhu, and Mindrila 2009). The resulting servitization variable has an average of 0 , a minimum of -3.75 and a maximum of 3.10 . Therefore, there are firms with low values of servitization; signalling that they are in initial stages in their service journey. At the same time, there are other firms with significantly higher values of servitization; implying that they have developed more service skills and have advanced further in the service continuum. We can further explore this heterogeneity to understand at which stage of the service continuum the moderation effect of product lifespan is stronger, i.e. testing Hypothesis 3. If, as was argued in the theoretical section, complex service business models are the ones that can 
benefit most from longer product lifespan, we should find that the moderation effect of product lifespan is particularly important for more advanced stages in the service continuum. To test this effect, we divide firms in three groups depending on their position in the service continuum: ${ }^{9}$

- Low-intensity: 62 firms with a servitization variable in the range $[-4,-1]$ are considered to be providing services as simple add-on to the product.

- Medium-intensity: 190 firms with a servitization variable in the range $(-1,1)$ are defined as selling intermediate services, but still placing a high relevance to the tangible nature of the offer.

- High-intensity: 49 firms with a servitization variable in the range [1, 4] are considered as selling advanced services

Table 4 column 4 reports the results of interacting product lifespan dummy and servitization at the different stages of the service continuum. In this case, for simplification and based on the Table 2, heavy equipment (with an average product lifespan of 16 years) is considered as long product lifespan and medical equipment (with an average product lifespan of 13 years) as short product lifespan. The baseline level is defined as base services and long product lifespan. Consistently with our predictions, results suggest that products with short product lifespan are best to limit themselves to low-intensity servitization $\left(\beta_{\text {Low\&SL }}=1.048\right.$; $\mathrm{p}$-value $\left.=0.095\right)$, whereas products with long product lifespan benefit most from medium-intensity $\left(\beta_{\text {Medium\&LL }}=\right.$ 1.299; $\mathrm{p}$-value $=0.027)$ and high-intensity $\left(\beta_{\text {High\&LL }}=2.333 ; \mathrm{p}\right.$-value $\left.=0.009\right)$ servitization. This result supports Hypothesis 3.

9. As we have arbitrarily created the cut off points. We attempted with a smaller range for intermediate services, but results are qualitatively the same. Results are available upon request. 
For more clarity on the interpretation of these parameters, we plot the predicted values in Figure 4. They show graphically that product lifespan influences the type of services that brings optimal profitability. Firms selling products with short lifespan outperform firms selling products with long lifespan when offering services as add-ons. However, once firms reach medium-intensity servitization, and especially when it comes to high-intensity-servitization, firms selling products with long lifespan outperform firms selling products with short lifespan. In order to evaluate the number of firms that actually benefit from implementing advanced service business models, Table 5 provides a cross tabulation between product lifespan and service continuum categories. According to Panel B, only 22 firms in the sample (7.3\%) are in the selected group of firms implementing high-intensity servitization and selling long lifespan products. Additionally, if we consider that industry determines product lifespan, we can also evaluate the percentage of firms choosing the optimal position in the service continuum. Within the group of firms that operate in short product lifespan industries, 36 out of 153 (23.5\%) operate at an optimal strategy by selling low-intensive services. Of the firms from long product lifespan industries, 14.8\% (22 out of 148) choose to operate at their optimal strategy by implementing business models with high-intensive services $(14.8 \%)$.

Table 5. Cross tabulation between product lifespan and service continuum

\begin{tabular}{|c|c|c|c|c|c|}
\hline \multicolumn{6}{|c|}{ PANEL A. MEDIUM PRODUCT LIFESPAN IS CONSIDERED } \\
\hline & & \multicolumn{3}{|c|}{ Product-lifespan } & Total \\
\hline & & Short & Middle & Long & \\
\hline \multirow[t]{4}{*}{ Service Continuum } & Low-intensity & 27 & 18 & 17 & 62 \\
\hline & Medium-intensity & 59 & 67 & 64 & 190 \\
\hline & High-intensity & 17 & 17 & 15 & 49 \\
\hline & Total & 103 & 102 & 96 & 301 \\
\hline \multicolumn{6}{|c|}{$\begin{array}{l}\text { PANEL B. MEDIUM PRODUCT LIFESPAN IS DROPPED, FIRMS INCLUDED IN OTHER } \\
\text { CATEGORIES }\end{array}$} \\
\hline & & \multicolumn{3}{|c|}{ Product-lifespan } & Total \\
\hline & & Short & Middle & Long & \\
\hline Service Continuum & Low-intensity & 36 & -- & 26 & 62 \\
\hline
\end{tabular}




\begin{tabular}{|l|l|c|c|c|c|}
\hline & Medium-intensity & 90 & -- & 100 & 190 \\
\cline { 2 - 6 } & High-intensity & 27 & -- & 22 & 49 \\
\hline & Total & 153 & -- & 148 & 301 \\
\hline
\end{tabular}

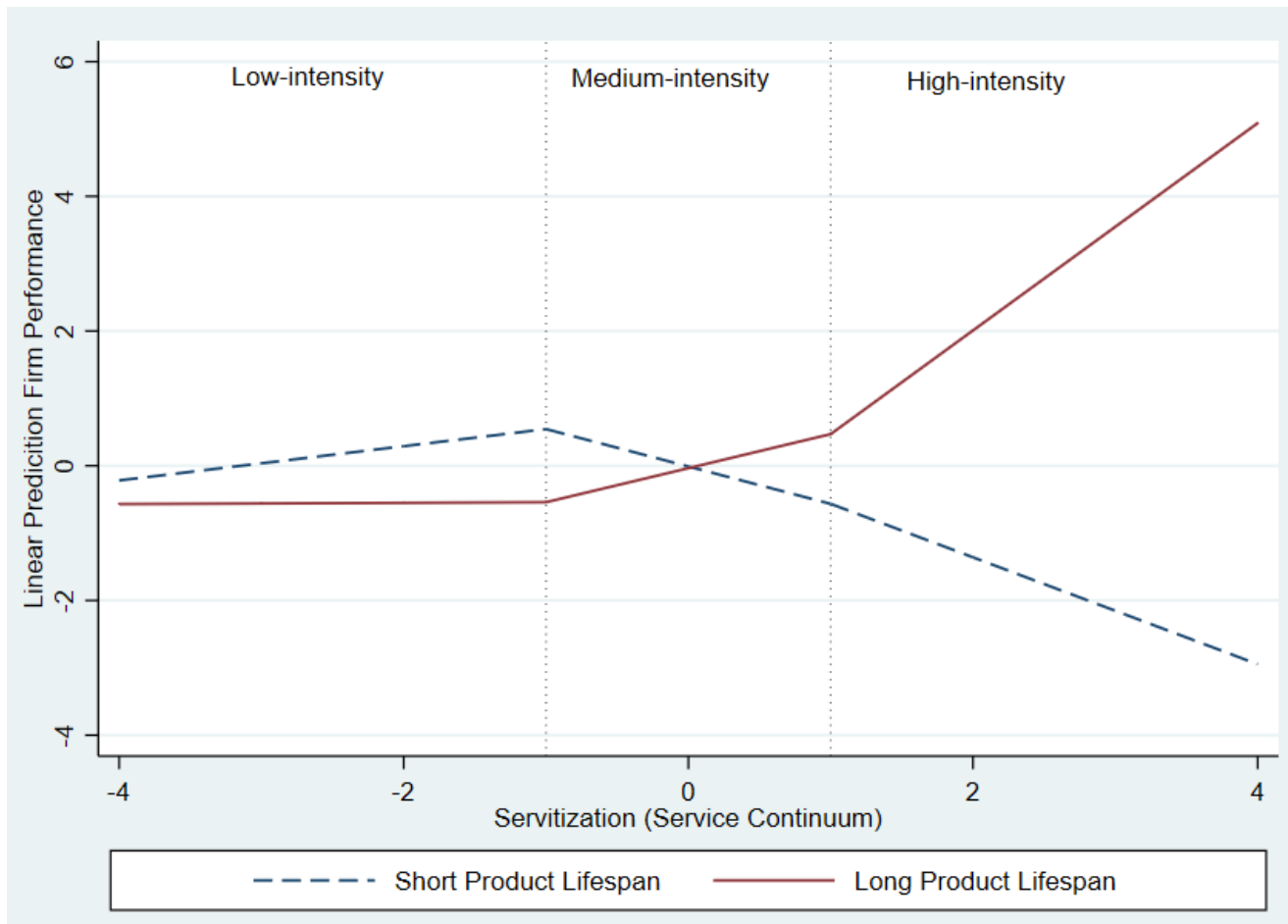

Figure 4. The moderating effect of product lifespan depending on the level of servitization

Table 3 column 4 reports the same analysis for the full sample, but introducing the continuous variable of product lifespan. The results of this estimation are qualitatively the same, the largest parameter is again the one corresponding to long product lifespan and high-intensity servitization $\left(\beta_{\text {High } \& L L}=0.0678\right.$; $\mathrm{p}$-value $\left.=0.009\right)$.

\section{Implications and concluding remarks}

The growing importance of services within the menu of products offered by manufacturers has become an increasingly noteworthy topic within the production management literature (Alghisi and Saccani 2015; Szász et al. 2017). This literature argues that manufacturing firms in the knowledge economy (Lafuente et al. 2017) are developing organizational competences related to servitization (Bustinza et al. 2017; Rabetino et al. 2018). These changes have been linked to the transition of manufacturers 
from a transaction-based product business model, towards one based on the delivery of solutions (Nordin and Kowalkowski 2010; Storbacka 2011; Visnjic et al. 2018). Because time and long-term customer relationship are essential factors for the successful transition towards solution business models (Storbacka et al. 2013), the study presented in this paper aimed to identify if the lifespan of the service-augmented products offered by BtoB manufacturers magnified the positive relation between servitization and business performance. As such, the study's results indicate that manufacturers with service-augmented products perform better; and that the greater the lifespan of the manufacturers' servitized products, the greater the resulting performance.

It is worth stressing the importance of this analysis. In line with Markides and Williamson (1994), our study concludes that in the context of an increasingly knowledge-based competitive environment, transactional strategies of product exploitation are insufficient in the long term. We show that BtoB multinationals that supply integrated product-service solutions through servitization are more successful when they offer products with long lifespans that have the time to generate synergetic value-added that is greater than the sum of its parts (Storbacka 2011). This is even more the case when advanced servitization strategies are implemented. An enduring servitization facilitates the development of joint competencies that enable customer embeddedness and the co-creation of advanced solutions which, in turn, helps to achieve a greater coverage of customers’ technological needs (Storbacka et al. 2012; Storbacka et al. 2013).

The results of this study have clear repercussions for managers and product developers of manufacturing firms, especially for those that commercialize BtoB products with potentially long lifespans. Development of service-based intangibles, or servitization, is an instrumental factor that enables these firms not only to maintain, but 
also to increase, their competitive advantage in the market. But whereas the transactional drive of many manufacturers adopting product-based business models has led them to cut down on the useful life of their products, the development of servitization strategies required in a knowledge-based competitive environment calls for manufacturers to extend product lifespan. The accelerated obsolescence used by many to increase the volume of transactions, repeat purchases and production scale is giving way to a high value-added, solution-driven and relational-based business model for which servitization is key to help manufacturers transition, and where product lifespan significantly contributes towards performance. Manufacturers should think more in terms of upgradable long-term solution delivery around advanced servitized platforms, rather than the standardized production of disposable goods. In an era of increasing social pressures for firms, especially manufacturers, to increase their social responsibility and reduce their environmental footprint, basing competitiveness on relational capital through long-term intangible-resource-reliant advanced servitization strategies can be considered as a much more sustainably favourable alternative to intensive tangible-resource-dependent transactional-based product business models.

Our study’s results indicate that manufacturers offering short-lifespan products find their performance hampered when delivering more advance levels of servitization (e.g. outcome base contracts). These firms can only benefit from a very basic level of servitization. The explanation for this result can be found within the solution business model literature, which suggests that the synergetic impact of offering integrated product-service system solutions requires time to establish true relational bond and customer embeddedness (Storbacka 2011; Storbacka et al. 2013). Short-term servitization normally generates service ‘add-ons’ to standardized products, that inevitably fail to fully capture the value-adding and performance enhancing potential of 
customized wholistic solution delivery. Developing the intangible relational capital that is required to establish the needed customer embeddedness for servitized solutions to optimize value necessitates time, effort and resource dedication. Additionally, firms selling products with short lifespan might not be able to extract value from outcome base contracts (i.e. long service lifespan) since replacement and information costs might undermine all the benefits associated to servitization (Hypko, Tilebein \& Gleich, 2010; Richter, Sadek \& Steven, 2010).

Manufacturers producing short lifespan servitized products may not only have difficulties optimizing their servitized value, they may be left with an insufficiently long relational investment cost recovery period. Thus, the issue of the contextualization of capitalization on intangible assets in long-term relationships is affected by our findings. To date, the literature has analysed this matter in contexts of product innovation (Danneels 2002; Lafuente, Vaillant, and Leiva 2018). Our study extends the analysis to models of service implementation in manufacturing.

The study provides managerial and policy implications. In an increasingly competitive business arena, most manufacturing firms are multi-product (Tang, Wang, and Fung 2000). According to our results, multi-product firms should differentiate their service strategies depending on the product lifespan. Organizational efforts towards the servitization journey should start with products with longer lifespan. Products with lower lifespan should embed low or medium intensity services, whilst products with longer lifespan should embed high intensity services. In addition, single product firms also can benefit from our evidence. Product lifespan can be modified by changing some product specifications (Kostecki 1998). Manufacturing firms interested in embarking on the servitization journey might decide to increase product lifespan to ensure cost recovery and enhance customer retention. This managerial recommendation also has an 
important implication for policy. Longer product lifespan means less production, more service-led activities and, hence, more sustainable production systems. European governments already promote the circular economy to ensure more sustainable manufacturing industries (de Man and Friege 2016). Our results suggest that servitization also should be an element to incorporate in manufacturing to increase product lifespan, which contraposes to transactional models of production based on scheduled obsolescence and continuous product replacement.

Although the uniqueness and richness of the data used in this study, a number of limitations remain. First, based on prior conventions established in the business model literature, we assume that industries with long product lifespan are more likely to develop customer embeddedness, solution integratedness, organizational networkedness, and operational adaptiveness as these are all found to be favoured by manufacturer-customer relational longevity. However, our lifespan variable does not account for intra-industry heterogeneity. Future studies on servitization and its relationship to customer embeddedness and solution integratedness should include variables connected to these constructs and to the contractual relationships with customers in order to obtain a more precise measure of product-service system specificity. Product lifespan is found to matter. But the amount of time that is necessary for customer embeddedness to take hold is likely to vary from one industry to another, from one firm to another, and even from one contractual relationship to another. Further research is needed to address this specific topic. Also, additional research should expand on weather manufacturer-customer relations based on multiple consecutive or simultaneous products (or solutions) serve to reach the same moderating impact on the servitization-performance correlation as that of a unique long-lifespan integrated 
solution. The results of our study would tend to indicate not, but more research is required to understand why.

Second, and related to previous point, whilst our analysis focuses on the most pertinent industries within the field of servitization (Bustinza et al. 2019), we use a wide industry classification that does not entirely capture intra-industry heterogeneity. Future studies should incorporate a more nuanced industry classification that can provide a more precise picture on how product lifespan affects servitization performance.

Third, the cross-sectional nature of the data used in the study does not allow for longitudinal heterogeneity analyses. As a result, future work based on longitudinal data seems decisive to better understand the temporal evolution of servitization strategies in businesses offering products with different lifespans. Finally, the conclusions generated in this study are the result of the analysis of large manufacturing multinational firms. We believe that our findings and recommendations can be extended to organizations with a heterogeneous product-service portfolio, for example, distinguishing between firms whose customers are end users and firms that sell their products-services to other organizations, or to other types of firms, such as large firms whose activity focuses more on local markets vs. small and medium-sized enterprises (SMEs). We therefore encourage researchers to engage in studies dealing with the wide-spectrum of valueadding effects of servitization ${ }^{10}$ strategies on business performance in smaller enterprises.

\section{References}

Abou-Foul, M., J. Ruiz-Alba, and A. Soares. 2020. “The Impact of Digitalization and Servitization on the Financial Performance: An Empirical Analysis.” Production Planning \& Control. doi: 10.1080/09537287.2020.1780508

10. See Bustinza et al. (2018) and Wang et al. (2018) for reviews on the servitizationperformance relationship for large firms. 
Acock, A. C. 2013. Discovering Structural Equation Modeling using Stata: Revised edition. College Station, TX: Stata Press.

Alghisi, A., and N. Saccani. 2015. "Internal and External Alignment in the Servitization Journey: Overcoming the Challenges.” Production Planning \& Control 26 (14-15): 12191232. doi: 10.1080/09537287.2015.1033496

Anderson, J. C., and J. A. Narus. 1991. "Partnering as a Focused Market Strategy.” California Management Review 33 ( 3): 95-113.

Armstrong, J. S., and T. S. Overton. 1977. "Estimating Nonresponse Bias in Mail Surveys.” Journal of Marketing Research 14 (3): 396-402. doi: 10.1177/002224377701400320

Ariu, A. 2016. "Crisis-proof Services: Why Trade in Services Did not Suffer During the 20082009 Collapse.” Journal of International Economics 98: 138-149. doi: 10.1016/j.jinteco.2015.09.002

Arrighetti, A., F. Landini, and A. Lasagni. 2014. "Intangible Assets and Firm Heterogeneity: Evidence from Italy.” Research Policy 43 (1): 202-213. doi: 10.1016/j.respol.2013.07.015

Baden-Fuller, C., and M. S. Morgan. 2010. "Business Models as Models.” Long Range Planning 43 (2-3): 156-171. doi: 10.1016/j.lrp.2010.02.005

Bagozzi, R. P. 2011. "Measurement and Meaning in Information Systems and Organizational Research: Methodological and Philosophical Foundations.” MIS Quarterly 35 (2): 261292. doi: $10.2307 / 23044044$

Baines, T., and H. Lightfoot. 2013. Made to Serve: How Manufacturers Can Compete through Servitization and Product Service Systems. London, UK: John Wiley \& Sons.

Baines, T., A. Bigdeli, A., O. F. Bustinza, V. Shi, J. S. Baldwin, and K. Ridgway. 2017. "Servitization: Revisiting the State-of-the art and Research Priorities." International Journal of Operations \& Production Management 37 (2): 256-278. doi: 10.1108/IJOPM06-2015-0312

Baines, T., A. Bigdeli, R. Sousa, and A. Schroeder. 2020. "Framing the Servitization Transformation Process: A Model to Understand and Facilitate the Servitization Journey.” International Journal of Production Economics 221: 107463. doi: 10.1016/j.ijpe.2019.07.036

Bastl, M., M. Johnson, H. Lightfoot, and S. Evans. 2012. "Buyer-supplier Relationships in a Servitized Environment.” International Journal of Operations \& Production Management 32 (6): 650-675. doi: 10.1108/01443571211230916

Belvedere, V., A. Grando, and P. Bielli. 2013. “A Quantitative Investigation of the Role of Information and Communication Technologies in the Implementation of a Product-Service System.” International Journal of Production Research 51 (2): 410-426. doi: 10.1080/00207543.2011.648278 
Bigdeli, A. Z., T. Baines, A. Schroeder, S. Brown, E. Musson, V. Guang Shi, and A. Calabrese. 2018a. "Measuring Servitization Progress and Outcome: The case of 'Advanced Services'.” Production Planning \& Control 29 (4): 315-332. doi: 10.1080/09537287.2018.1429029

Bigdeli, A. Z., O. F. Bustinza, F. Vendrell-Herrero, and T. Baines. 2018b. "Network Positioning and Risk Perception in Servitization: Evidence from the UK Road Transport Industry.” International Journal of Production Research 56 (6): 2169-2183. doi: 10.1080/00207543.2017.1341063

Bustinza, O. F., A. Z. Bigdeli, T. Baines, and C. Elliot. 2015. "Servitization and Competitive Advantage: The Importance of Organizational Structure and Value Chain Position.” Research-Technology Management 58 (5): 53-60. doi: 10.5437/08956308X5805354

Bustinza, O. F., F. Vendrell-Herrero, and T. Baines. 2017. "Service Implementation in Manufacturing: An Organisational Transformation Perspective.” International Journal of Production Economics 192: 1-8. doi: 10.1016/j.ijpe.2017.08.017

Bustinza, O. F., E. Gomes, F. Vendrell-Herrero, and T. Baines. 2019. "Product-Service Innovation and Performance: The Role of Collaborative Partnerships and R\&D Intensity.” R\&D Management 49 (1): 33-45. doi: 10.1111/radm.12269

Bustinza, O. F., F. Vendrell-Herrero, E. Gomes, E. Lafuente, M. Opazo-Basáez, R. Rabetino, and Y. Vaillant. 2018. "Product-Service Innovation and Performance.” International Journal of Business Environment, 10 (2): 95-111. doi: 10.1504/IJBE.2018.095819

Bustinza, O. F., E. Lafuente, R. Rabetino, Y. Vaillant, and F. Vendrell-Herrero. 2019. "Makeor-buy Configurational Approaches in Product-Service Ecosystems and Performance.” Journal of Business Research. 104: 393-401. doi: 10.1016/j.jbusres.2019.01.035

Calabrese, A., N. Levialdi Ghiron, L. Tiburzi, T. Baines, and A. Z. Bigdeli. 2019. "The Measurement of Degree of Servitization: Literature Review and Recommendations.” Production Planning \& Control 30 (13): 1118-1135. doi: 10.1080/09537287.2019.1592260

Chang, S. J., A. Van Witteloostuijn, and L. Eden. 2010. "From the Editors: Common Method Variance in International Business Research.” Journal of International Business Studies 41 (2): 178-184. doi: 10.1057/jibs.2009.88

Cheng, Y., and J. Johansen. 2014. “Operations Network Development: Internationalisation and Externalisation of Value Chain Activities.” Production Planning \& Control 25 (16): 13511369. doi: 10.1080/09537287.2013.839064

Cheng, Y., A. Chaudhuri, and S. Farooq. 2016. "Interplant Coordination, Supply Chain Integration, and Operational Performance of a Plant in a Manufacturing Network: A Mediation Analysis.” Supply Chain Management: An International Journal 21 (5): 550568. doi: 10.1108/SCM-10-2015-0391 
Dachs, B., S. Kinkel, and A. Jäger. 2019. "Bringing it all Back Home? Backshoring of Manufacturing Activities and The Adoption of Industry 4.0 Technologies.” Journal of World Business, 54 (6): 101017. doi: 10.1016/j.jwb.2019.101017

Danneels, E. 2002. “The Dynamics of Product Innovation and Firm Competences.” Strategic Management Journal 23 (12): 1095-1121. doi: 10.1002/smj.275

Davies, A. 2004. "Moving Base into High-Value Integrated Solutions: A Value Stream Approach.” Industrial and Corporate Change 13 (5): 727-756. doi: 10.1093/icc/dth029 de Man, R., and H. Friege. 2016. "Circular Economy: European Policy on Shaky Ground.” Waste Management \& Research 34 (2): 93-95. doi: 10.1177/0734242X15626015

Dmitrijeva, J., A. Schroeder, A. Z. Bigdeli, and T. Baines. 2019. “Context Matters: How Internal and External Factors Impact Servitization.” Production Planning \& Control. doi: 10.1080/09537287.2019.1699195

DiStefano, C., M,. Zhu, and D. Mindrila. 2009. “Understanding and Using Factor Scores: Considerations for the Applied Researcher.” Practical Assessment, Research \& Evaluation 14 (20): 1-11. doi: 10.7275/da8t-4g52

Fischer, T., H. Gebauer, and E. Fleisch. 2012. Service Business Development: Strategies for Value Creation in Manufacturing Firms. Cambridge, UK: Cambridge University Press.

Foster, L., C. Grim, J. Haltiwanger, and Z. Wolf. 2016. "Firm-Level Dispersion in Productivity: Is the Devil in the Details?.” American Economic Review 106 (5): 95-98. doi: 10.1257/aer.p20161023

Ganotakis, P., W. L. Hsieh, and J. H. Love. 2013. “Information Systems, Inter-Functional Collaboration and Innovation in Taiwanese High-Tech Manufacturing Firms.” Production Planning \& Control 24(8-9): 837-850. doi: 10.1080/09537287.2012.666876

Gebauer, H., and T. Friedli. 2005. "Behavioral Implications of the Transition Process from Products to Services.” Journal of Business \& Industrial Marketing 20 (2): 70-78. doi: 10.1108/08858620510583669

Gebauer, H., M. Paiola, and N. Saccani. 2013. “Characterizing Service Networks for Moving from Products to Solutions.” Industrial Marketing Management 42 (1): 31-46. doi: 10.1016/j.indmarman.2012.11.002

Grant, R. M., and C. Baden-Fuller. 2004. "A Knowledge Accessing Theory of Strategic Alliances.” Journal of Management Studies 41 (1): 61-84. doi: 10.1111/j.14676486.2004.00421.x

Gustafsson, A., B. Edvardsson, and S. Brax. 2005. “A Manufacturer Becoming Service Provider-Challenges and a Paradox.” Managing Service Quality: An International Journal 15 (2): 142-155. doi: 10.1108/09604520510585334

Hair, J. F., R. E. Anderson, R. L. Tatham, and W. Black. 2001. Multivariate Data Analysis. London, UK: Prentice-Hall Pearson Education. 
Heiberger, R. M., and N. B. Robbins. 2014. "Design of Diverging Stacked Bar Charts for Likert Scales and other Applications.” Journal of Statistical Software 57 (5): 1-32.

Helander, A., and C. Möller. 2007. “System Supplier’s Customer Strategy.” Industrial Marketing Management 36 (6): 719-730. doi: 10.1016/j.indmarman.2006.05.007

Hou, J., and A. Neely. 2018. "Investigating Risks of Outcome-based service Contracts from a Provider’s Perspective.” International Journal of Production Research 56 (6)_2103-2115. doi: 10.1080/00207543.2017.1319089

Hypko, P., Tilebein, M., and Gleich, R. 2010. "Benefits and uncertainties of performance-based contracting in manufacturing industries”. Journal of Service Management, 21(4): 460. doi: $10.1108 / 09564231011066114$

Imbens, G. W., and M. Kolesar. 2016. "Robust Standard Errors in Small Samples: Some Practical Advice.” Review of Economics and Statistics 98 (4): 701-712. doi: 10.1162/REST_a_00552

Johansson, J. E., Krishnamurthy, C., \& Schlissberg, H. E. (2003). Solving The Solutions Problem. The Mckinsey Quarterly, 3, 116-125.

Kamp, B. 2019. "Restructuring for Service Business Development: Insights from a Machine Tool Manufacturer.” International Journal of Business Environment 10 (4), 281-305. doi: 10.1504/IJBE.2019.101643

Kharlamov, A. A., and G. Parry. 2020. "The Impact of Servitization and Digitization on Productivity and Profitability of the Firm: A Systematic Approach.” Production Planning \& Control In Press. doi: 10.1080/09537287.2020.1718793

Kim, Y., and R. E. Ployhart. 2018. “The Strategic Value of Selection Practices: Antecedents and Consequences of Firm-Level Selection Practice Usage.” Academy of Management Journal 61 (1): 46-66. doi: 10.5465/amj.2015.0811

Kohtamäki, M., J. Partanen, V. Parida, and J. Wincent. 2013. “Non-Linear Relationship between Industrial Service Offering and Sales Growth: The Moderating Role of Network Capabilities.” Industrial Marketing Management 42 (8): 1374-1385. doi: 10.1016/j.indmarman.2013.07.018

Kostecki, M. 1998. "Product Durability and Marketing Strategies.” In The Durable Use of Consumer Products, edited by Michel Kostecki, 41-49. Boston, MA: Springer. doi: 10.1007/978-1-4757-2819-4

Kowalkowski, C., H. Gebauer, B. Kamp, and G. Parry. 2017. "Servitization and Deservitization: Overview, Concepts, and Definitions.” Industrial Marketing Management 60: 4-10. doi: 10.1016/j.indmarman.2016.12.007

Lafuente, E., Y. Vaillant, and F. Vendrell-Herrero. 2017. “Territorial Servitization: Exploring the Virtuous Circle Connecting Knowledge-Intensive Services and New Manufacturing 
Businesses.” International Journal of Production Economics 192: 19-28. doi:

10.1016/j.ijpe.2016.12.006

Lafuente, E., Y. Vaillant, and J. C. Leiva. 2018. “Sustainable and Traditional Product Innovation without Scale and Experience, but Only For KIBS!.” Sustainability 10 (4): 1169-1187. doi: 10.3390/su10041169

Lee, H. L. 2002. “Aligning supply chain strategies with product uncertainties.” California Management Review 44 (3): 105-119. doi: 10.2307/41166135

Lee, S., S. Yoo, and D. Kim. 2016. "When is Servitization a Profitable Competitive Strategy?.” International Journal of Production Economics 173, 43-53. doi: 10.1016/j.ijpe.2015.12.003

Li, J. H., L. Lin, D. Chen, and L. Y. Ma. 2015. “An Empirical Study of Servitization Paradox in China.” Journal of High Technology Management Research 26 (1): 66-76. doi: 10.1016/j.hitech.2015.04.007

Li, R., Y. Liu, and O. F. Bustinza. 2018. "FDI, Service Intensity, and International Marketing Agility: The Case Of Export Quality of Chinese Enterprises.” International Marketing Review 36 (2): 213-238.

Markides, C. C. and P. J. Williamson. 1994. "Related Diversification, Core Competences and Corporate Performance.” Strategic Management Journal 15 (52): 149-165. doi: 10.1002/smj.4250151010

Mathieu, V. 2001. "Service Strategies within the Manufacturing Sector: Benefits, Costs and Partnership.” International Journal of Service Industry Management 12 (5): 451-475. doi: 10.1108/EUM0000000006093

Min, H., J. Park, and H. J. Kim. 2016. “Common Method Bias in Hospitality Research: A Critical Review of Literature and an Empirical Study.” International Journal of Hospitality Management 56: 126-135. doi: 10.1016/j.ijhm.2016.04.010

Müller, O., M. Fay, and J. Vom Brocke. 2018. “The Effect of Big Data and Analytics on Firm Performance: An Econometric Analysis Considering Industry Characteristics.” Journal of Management Information Systems 35 (2): 488-509. doi: 10.1080/07421222.2018.1451955

Murakami, S., M. Oguchi, T. Tasaki, I. Daigo, and S. Hashimoto. 2010. "Lifespan of Commodities, Part I: The Creation of a Database and its Review.” Journal of Industrial Ecology 14 (4): 598-612. doi: 10.1111/j.1530-9290.2010.00250.x

Na, Y. K., S. Kang, and H. Y. Jeong. 2019. "The Effect of Market Orientation on Performance of Sharing Economy Business: Focusing on Marketing Innovation and Sustainable Competitive Advantage.” Sustainability 11 (3): 729-748. doi: 10.3390/su11030729

Ng, I., G. Parry, L. Smith, R. Maull, and G. Briscoe. 2012. “Transitioning from a GoodsDominant to a Service-Dominant Logic: Visualising the Value Proposition of Rolls- 
Royce.” Journal of Service Management 23 (3): 416-439. doi:

$10.1108 / 09564231211248480$

Ng, I. C., Ding, D. X., and N. Yip. 2013. “Outcome-based Contracts as New Business Model:

The Role of Partnership and Value-driven Relational Assets.” Industrial Marketing

Management 42 (5): 730-743. doi: 10.1016/j.indmarman.2013.05.009

Nordin, F., and C. Kowalkowski. 2010. "Solutions Offerings: A Critical Review and

Reconceptualisation.” Journal Of Service Management 21 (4): 441-459. doi:

10.1108/09564231011066105

Oliva, R., and R. Kallenberg. 2003. "Managing the Transition from Products to Services.” International Journal of Service Industry Management 14 (2): 160-172. doi: 10.1108/09564230310474138

Oguchi, M., S. Murakami, T. Tasaki, I. Daigo, and S. Hashimoto. 2010. "Lifespan of Commodities, Part II: Methodologies for Estimating Lifespan Distribution of Commodities.” Journal of Industrial Ecology 14 (4): 613-626. doi: 10.1111/j.15309290.2010.00251.x

Paiola, M., Saccani, N., Perona, M., and H. Gebauer. 2013. "Moving from Products to Solutions: Strategic Approaches for Developing Capabilities.” European Management Journal 31 (4), 390-409. doi: 10.1016/j.emj.2012.10.002

Parida, V., D. Sjödin, and W. Reim. 2019. "Reviewing Literature on Digitalization, Business Model Innovation, and Sustainable Industry: Past Achievements and Future Promises.” Sustainability 11 (2): 391. doi: 10.3390/su11020391

Press, W. H., S. A. Teukolsky, W. T. Vetterling, and B. P. Flannery. 2007. Numerical Recipes 3rd Edition: The Art of Scientific Computing. Cambridge, MA: Cambridge University Press.

Rabetino, R., M. Kohtamäki, and H. Gebauer. 2017. "Strategy Map of Servitization.” International Journal of Production Economics 192: 144-156. doi: 10.1016/j.jpe.2016.11.004

Rabetino, R., W. Harmsen, M. Kohtamäki, and J. Sihvonen. 2018. "Structuring ServitizationRelated Research.” International Journal of Operations \& Production Management 38 (2): 350-371. doi: 10.1108/IJOPM-03-2017-0175

Rapaccini, M. and F. Visintin. 2015. "Devising Hybrid Solutions: An Exploratory Framework.” Production Planning \& Control, 26 (8): 654-672. doi: 10.1080/09537287.2014.961106

Richardson, H. A., M. J. Simmering, and M. C. Sturman. 2009. “A Tale of Three Perspectives: Examining Post Hoc Statistical Techniques for Detection and Correction of Common Method Variance.” Organizational Research Methods 12 (4): 762-800. doi: 10.1177/1094428109332834 
Richter, A., Sadek, T., and Steven, M. 2010. "Flexibility in industrial product-service systems and use-oriented business models”. CIRP journal of manufacturing science and technology, 3(2): 128-134. doi: https://doi.org/10.1016/j.cirpj.2010.06.003

Simmering, M. J., C. M. Fuller, H. A. Richardson, Y. Ocal, and G. M. Atinc. 2015. "Marker Variable Choice, Reporting, and Interpretation in the Detection of Common Method Variance: A Review and Demonstration.” Organizational Research Methods 18 (3): 473 511. doi: 10.1177/1094428114560023

Sjödin, D., V. Parida, M. Kohtamäki, and J. Wincent. 2020. “An Agile Co-Creation Process for Digital Servitization: A Micro-Service Innovation Approach.” Journal of Business Research 112: 478-491. doi: 10.1016/j.jbusres.2020.01.009

Smith, D. J. 2013. "Power-By-The-Hour: The Role of Technology in Reshaping Business Strategy at Rolls-Royce.” Technology Analysis \& Strategic Management 25 (8): 987-1007. doi: 10.1080/09537325.2013.823147

Sousa, R., and G. J. Da Silveira. 2017. "Capability Antecedents and Performance Outcomes of Servitization: Differences Between Basic and Advanced Services.” International Journal of Operations \& Production Management 37 (4): 444-467. doi: 10.1108/IJOPM-11-20150696

Storbacka, K., and S. Nenonen. 2009. "Customer Relationships and the Heterogeneity of Firm Performance.” The Journal of Business and Industrial Marketing 24 (5/6): 360-372. doi: 10.1108/08858620910966246

Storbacka, K. 2011. “A Solution Business Model: Capabilities and Management Practices for Integrated Solutions.” Industrial Marketing Management 40 (5): 699-711. doi: 10.1016/j.indmarman.2011.05.003

Storbacka, K., P. Frow, S. Nenonen, and P. Payne. 2012. “Designing Business Models for CoCreation.” In Towards a Better Understanding of the Role of Value in Markets and Marketing, edited by Vargo, S. L., and R. F. Lusch, 51-78. Bingley, UK: Emerald Group Publishing.

Storbacka, K., C. Windahl, S. Nenonen, and A. Salonen. 2013. “Solution Business Models: Transformation along Four Continua.” Industrial Marketing Management 42 (5): 705-716. doi: 10.1016/j.indmarman.2013.05.008

Sturgeon, T. J. 2002. “Modular Production Networks: A New American Model of Industrial Organization.” Industrial and Corporate Change 11 (3): 451-496. doi: 10.1093/icc/11.3.451

Szász, L., K. Demeter, H. Boer, and Y. Cheng. 2017. "Servitization of Manufacturing: The Effect of Economic Context.” Journal of Manufacturing Technology Management 28 (8): 1011-1034. doi: 10.1108/JMTM-11-2016-0166 
Tang, J., D. Wang, and R. Y. Fung. 2000. “Fuzzy Formulation for Multi-Product Aggregate Production Planning.” Production Planning \& Control 11 (7): 670-676. doi: 10.1080/095372800432133

Teece, D. J. 1998. “Capturing Value from Knowledge Assets: The New Economy, Markets for Know-How, and Intangible Assets.” California Management Review 40 (3): 55-79.

Tukker, A. 2004. "Eight Types of Product-Service System: Eight Ways to Sustainability? Experiences from Suspronet.” Business Strategy and The Environment 13 (4): 246-260. doi: 10.1002/bse.414

Turunen, T. T., and M. Toivonen. 2011. “Organizing Customer-Oriented Service Business in Manufacturing.” Operations Management Research 4 (1-2): 74-84. doi: 10.1007/s12063011-0047-5

Ulaga, W., and W. J. Reinartz. 2011. "Hybrid Offerings: How Manufacturing Firms Combine Goods and Services Successfully.” Journal of Marketing 75 (6): 5-23. doi: 10.1509/jm.09.0395

Valtakoski, A., and L. Witell. 2018. "Service Capabilities and Servitized SME Performance: Contingency on Firm Age.” International Journal of Operations \& Production Management 38 (4): 1144-1164. doi: 10.1108/IJOPM-06-2016-0328

Vandermerwe, S., and J. Rada. 1988. "Servitization of Business: Adding Value by Adding Services.” European Management Journal 6 (4): 314-324. doi: 10.1016/02632373(88)90033-3

Vendrell-Herrero, F., E. Gomes, O. F. Bustinza, and K. Mellahi. 2018. "Uncovering the Role of Cross-Border Strategic Alliances and Expertise Decision Centralization in Enhancing Product-Service Innovation in MMNEs.” International Business Review 27 (4): 814-825. doi: 10.1016/j.ibusrev.2018.01.005

Vendrell-Herrero, F., O. F. Bustinza, and M. Opazo-Basaez. 2020. "Information Technologies and Product-Service Innovation: The Moderating Role of Service R\&D Team Structure.” Journal of Business Research In Press. doi: 10.1016/J.Jbusres.2020.01.047

Vendrell-Herrero, F., C. Darko, Y. Vaillant. 2020. "Firm productivity and government contracts: The moderating role of corruption.” Socio-Economic Planning Sciences. doi: 10.1016/j.seps.2020.100899

Visnjic, I., M. Jovanovic, A. Neely, and M. Engwall. 2017. "What Brings the Value to Outcome-Based Contract Providers? Value Drivers in Outcome Business Models.” International Journal of Production Economics 192: 169-181. doi: 10.1016/j.ijpe.2016.12.008

Visnjic, I., A. Neely, and M. Jovanovic. 2018. “The Path to Outcome Delivery: Interplay of Service Market Strategy and Open Business Models.” Technovation 72-73: 46-59. doi: 10.1016/j.technovation.2018.02.003 
Wang, W., K. H. Lai, and Y. Shou. 2018. “The Impact of Servitization on Firm Performance: A Meta-Analysis.” International Journal of Operations \& Production Management 38 (7): 1562-1588. doi: 10.1108/IJOPM-04-2017-0204

Wise, R., and P. Baumgartner. 1999. “Go Downstream: The New Profit Imperative in Manufacturing.” Harvard Business Review 77(5): 133-141.

Yang, Z., and R. T. Peterson. 2004. "Customer Perceived Value, Satisfaction, and Loyalty: The Role of Switching Costs.” Psychology \& Marketing 21 (10): 799-822. doi:

10.1002/mar.20030

Zhou, D., T. Yan, L. Zhao, and J. Guo. 2020. "Performance Implications of Servitization: Does a Manufacturer's Service Supply Network Matter?.” International Journal of Production Economics 219: 31-42. doi: 10.1016/j.ijpe.2019.05.019 